\title{
STUDY OF LIQUID-LIQUID SLUG BREAK UP MECHANISM IN A MICROCHANNEL T-JUNCTION AT VARIOUS MODIFIED WEBER NUMBER
}

\author{
JiTKAI CHIN \\ Department of Chemical and Environmental Engineering, \\ University of Notitngham Malaysia Campus, Jalan Broga, 43500 Semenyih, \\ Selangor Darul Ehsan, Malaysia. \\ Jit-Kai.Chin@nottingham.edu.my
}

\begin{abstract}
The formation of immiscible liquid slugs shows various potential applications in different fields because of absolute control of the species both spatially and temporally, as well as enhanced mixing efficiency. Although applications of droplet/slug based microfluidics have been widely demonstrated, the fundamental physics governing slug/ droplet break-up remains to be an area of active research. This study defines an effective Weber Number $\left(W e_{\text {eff }}\right)$ that characterizes the interplay of interfacial tension, shear stress and dynamic pressure in the micro-channel. Qualitative results show that, at relatively low $W e_{\text {eff; }}$, hydrodynamic force plays an important role in slug break- up at the micro-channel T-junction. At intermediate $W e_{e f f}$, both shear force and hydrodynamic force play an equally important role in slug break up. At relatively high $W e_{e f f}$, shear force is dominant in slug break up at the T-junction.
\end{abstract}

ABSTRAK: Pembentukan slug cecair likat tidak bercampur mempunyai potensi di dalam pelbagai bidang kerana daya kawalan mutlak spesis tersebut secara spasial dan temporal, serta kecekapan pencampuran. Walaupun aplikasi titisan/ likat mikrofluida telah didemonstrasi secara meluas, kajian fizik asas yang menentukan pemecahan likat/ titisan masih menjadi bahan kajian yang aktif. Kajian ini mentakrifkan nombor Weber efektif $\left(W e_{\text {eff }}\right)$ yang mengaitkan ketegangan antara permukaan, tekanan ricih dan tekanan dinamik di dalam saluran mikro. Keputusan kualitatif menunjukkan bahawa, pada $W e_{\text {eff }}$ yang rendah, daya hidrodinamik memainkan peranan penting dalam pemecahan likat di persimpangan $\mathrm{T}$ saluran micro. Pada $W e_{\text {eff }}$ perantaraan, daya ricih dan daya hidrodinamik memainkan peranan yang penting dalam pemecahan slug. Pada $W e_{\text {eff }}$ yang relatifnya tinggi, daya ricih adalah dominan di dalam pemecahan likat di persimpangan $\mathrm{T}$.

KEYWORDS: liquid-liquid slug break-up, modified Weber Number, hydrodynamic force

\section{INTRODUCTION}

Slug forms spontaneously when two immiscible liquids are brought into contact in a T-junction micro-channel at appropriate flow rates. The potential application of slug-based microfluidics has been demonstrated since years ago and attracted attention from researchers because of the absolute control on species both spatially and temporally, as 
well as internal recirculation in the slug itself, induced by radial shearing along the channel enhances mass transfer that translates into a decrease of mixing time.

Although the technique has been widely demonstrated in various applications [1-6], the discussion in the mechanism of slug break up in an immiscible liquid-liquid phase is seldom reported. The present study experimentally observes the dynamic evolution of droplet interfaces and flow patterns that precede a slug break up event in a T-junction microchannel. Interplay of interfacial tension, shear stress and pressure drop in driving the mechanism of break up at various flow rates were investigated.

\section{THEORY}

Slug break up has been studied for decades by carrying out experiments in millimetre scaled capillary tubes. Although the scale discussed in the paper is larger than micrometer, some of the models and the ensuing understanding are relevant to the work.

Deformation of a droplet is affected by the external flow pattern and physical properties of both the disperse phase and the continuous phase [7]. Force of inertia, shear stress, interfacial tension and viscosities ratio are the important parameters that act on the droplet which result in its deformation and break up. Hence the Weber Number $(\mathrm{We})$ was proposed to describe the phenomenon.

Investigation on droplet end-pinching and break up mechanism in large scale horizontal flow show that breakup of the two-phases flow is due to both shear stress and external pressure field applied by the continuous phase [8]. The imposed shear flow and interfacial tension act in opposite directions, in which imposed shear flow acts to deform the disperse phase while the interfacial tension tends to maintain its shape. The shear stress induces changes in the shape of the extruding disperse phase, causing the asymmetrical shape in disperse phase.

The parameters laid the foundation for droplet and slug formations, which are simplified into two dimensionless numbers. The Weber Number, We and Capillary Number, $\mathrm{Ca}$, respectively are defined as:

$$
\begin{gathered}
\text { Weber Number }=\frac{\text { inertia force }}{\text { interfacial force }} \quad W e=\frac{\rho u^{2} D}{\gamma} \\
\text { Capillary Number }=\frac{\text { viscous force }}{\text { interfacial tension }} \quad C a=\frac{u \mu}{\gamma}
\end{gathered}
$$

Several models are proposed for the disintegration of droplet and slug break up in a microchannel configuration. The size of droplet produced under external shear force is a product of the balance between the shear forces with Laplace pressure [9], based on the derivation of viscosity, leading to equation 3.

$$
r \sim \frac{\gamma}{\mu G}
$$

In which the shear rate is estimated from Hagen Poiseuille equation, 


$$
G \sim \frac{2 v_{g a p}}{d}
$$

Further investigations show [2-3] that the slug formation at a microchannel T-junction is independent of $\mathrm{Ca}$ but highly dependent of the flow ratio of the disperse phase to the continuous phase. Their results also show that capillarity is no longer valid when $C a>>1$ x $10^{-3}$, in which slug break up occurs further downstream in the main channel but not at the T-junction. Further research reveals that slug break up is affected by viscosity of the continuous phase. These work shows that different shear forces applied at the interface might affect the range of each regime [3].

Extensive work also suggests that hydrodynamic force is also one of the important parameters in producing slugs in microchannels, rather than shear stress acting at the liquid-liquid interface [10], which draws conclusion that liquid-liquid slug break up is due to higher magnitudes of hydrodynamic force. However, the experiment only focuses on moderate operating range in which steady slug formation occurs, neglecting slug formation in the disperse phase laminar flow region in the main channel downstream. Notwithstanding, the result is consistent with the findings of Ismagilov et al. [2-3], in which $\mathrm{Ca}$ is not an appropriate parameter in characterisation of slug formation in microchannel since the flow dynamic is the most important factor in driving slug break up.

In which case, the utilisation of We as a characterisation parameter is recommended. In addition, an effective viscosity is required in a two-phase system as both phases contribute to the shear stress. Hence, a modified $W e$ is used for the characterisation, involving the effective viscosity, $\rho$; continuous phase velocity, $v_{\text {cont }}$; as well as the hydrodynamic diameter, $d_{\text {hyd }}$; which is shown in Equation 5.

$$
W e_{\text {eff }}=\frac{\rho_{\text {eff }} v_{\text {cont }}{ }^{2} d_{\text {hyd }}}{\gamma}
$$

\subsection{Interfacial Tension}

As disperse phase slug grows in the main channel, the surface area of the disperse phase rear interface in the T-junction varies with time because of the different degree of tangential stress on it by the upstream continuous phase flow. The undefined contact line and unpredictable shape of the rear interface result in spatial and temporal interfacial force changes. Hence, it is calculated based on the surface area estimated from images taken during experiment.

Assuming the shape of the slug is limited by the dimension of the channel and the cross sectional area of the microchannel equivalent to a bowl shape, the interfacial forces are equivalent to:

$$
\begin{aligned}
& \Delta P \sim-\gamma\left(\frac{1}{w}\right) \\
& A=(w-2 h) h+\frac{\pi h^{2}}{2}
\end{aligned}
$$




$$
\begin{aligned}
& F_{\gamma} \sim-\gamma\left(\frac{2}{w}+\frac{2}{h}\right) *\left[(w-2 h) h+\frac{\pi h^{2}}{2}\right] \\
& F_{\gamma} \sim-\frac{\gamma}{w} *\left[(w-2 h) h+\frac{\pi h^{2}}{2}\right]
\end{aligned}
$$

\subsection{Shear Force}

Similar to calculation of interfacial forces, the contact area between the immiscible phases is important in calculating the shear force. Calculation of the shear force is difficult because it depends on the contact between both phases, based on images taken during the experiment.

$$
F_{\tau}=\mu \mathrm{GA}
$$

\subsection{Hydrodynamic Force}

The hyrodynamic force including both the pressure drop along the main channel well as capillary force across interface, is shown in Equation 11.

$$
\Delta P=\Delta P_{h, c o n t}+\Delta P_{h, d i s}+\Delta P_{C}
$$

Since it is not possible to measure pressure force along the flow direction, Hagen Poiseuille equation is used in estimating pressure drop along the channel in the flow direction, including both disperse phase slug and continuous phase slug, as shown in Equation 12 and Equation 13. From the pressure drop, forces acting at the rear interface are calculated by multiplying the pressure by the cross sectional area, as shown in Fig. 1.

$$
\begin{aligned}
& \Delta P_{h, \text { tot }}=\Delta P_{h, \text { dis }}+\Delta P_{h, \text { cont }} \\
& \Delta P_{h, \text { tot }}=\frac{128 Q_{\text {dis }}}{\pi D_{\text {hyd }}^{4}} \mu_{\text {dis }} L_{\text {dis }}+\frac{128 Q_{\text {cont }}}{\pi D_{\text {hyd }}^{4}} \mu_{\text {cont }} L_{\text {cont }}
\end{aligned}
$$

Capillary pressure drop is calculated based on Lucas-Washburn equation, including the differences between the receding contact angle and the advancing contact angle, located at the front interface and the rear interface of the slug respectively, which are included in Equation 14.

$$
\Delta P_{C a p}=\gamma\left[\left(\frac{2}{r_{w}} \cos \theta_{r}+\frac{2}{r_{h}} \cos \theta_{r}\right)-\left(\frac{2}{r_{w}} \cos \theta_{a}+\frac{2}{r_{h}} \cos \theta_{a}\right)\right]
$$




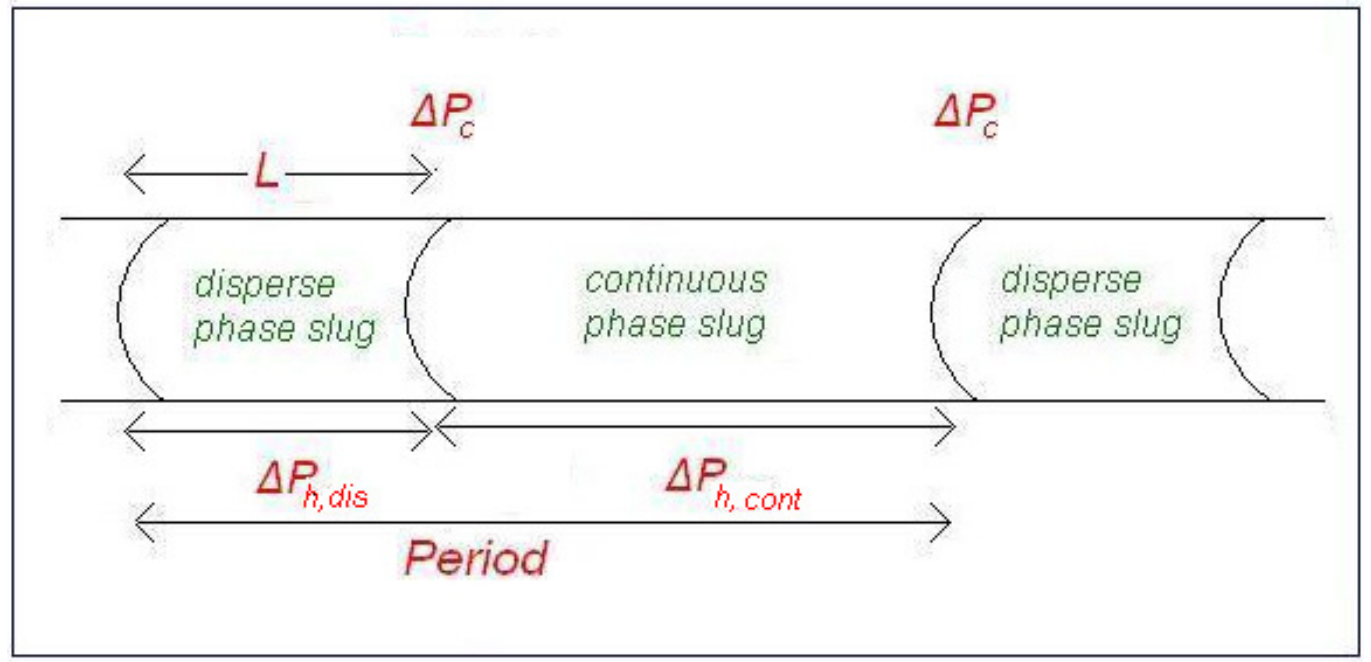

Fig. 1: Schematic description of liquid-liquid slug phase flow along the main channel. It is equivalent to a capillary flow in which the hydrodynamic pressure drop along the channel caused by each phase and the pressure drop across the interphase is calculated.

The total hydrodynamic force is a combination of hydrodynamic pressure drop and capillary pressure drop over the cross sectional area of the channel, given in Equation 15.

$$
\begin{aligned}
& \left.F_{t}=A \mid\left(\Delta P_{h, t o t}\right)+\left(\Delta P_{\text {cap }}\right)\right\rfloor \\
& \Delta P_{\text {Cap }}=A\left\{\begin{array}{l}
{\left[\begin{array}{l}
\left.\frac{128 Q_{\text {dis }}}{\pi D_{h y d}} \mu_{d i s} L_{d i s}+\frac{128 Q_{\text {cont }}}{\pi D_{h y d}} \mu_{\text {cont }} L_{\text {cont }}\right] \\
+\gamma\left[\left(\frac{2}{r_{w}} \cos \theta_{r}+\frac{2}{r_{h}} \cos \theta_{r}\right)-\left(\frac{2}{r_{w}} \cos \theta_{a}+\frac{2}{r_{h}} \cos \theta_{a}\right)\right]
\end{array}\right\}}
\end{array}\right.
\end{aligned}
$$

\section{EXPERIMENT}

Before the experiment, the properties of the chemicals are investigated. The experiment is carried out in a glass microchannel network fabricated with conventional wet etching method involving Fluoric Acid (HF) [11]. The channel has a bowl-shape dimension and consists of 2 simple T-junctions. However, only a junction was involved in this experiment. The top dimension of the channel is equivalent to $245 \mu \mathrm{m}$ while the height of the channel is equivalent to $50 \mu \mathrm{m}$.

Tetradecane and acetonitrile (Sigma, 99\% purity) are used as disperse phase and continuous phase respectively in this experiment. During experiment, the disperse phase is delivered from the side channel while the continuous phase is delivered into the main channel using standard syringe (BD Plastic), driven by a syringe pump (NE-1000, New Era Pump System Inc.). 


\subsection{Method}

The microchannel network was mounted onto a light inverted microscope platform before acetonitrile and tetradecane were injected into the device, driven by a syringe pump. The flowrate into the microchannel network is controlled from the digital panel on the syringe pump. Velocities for disperse phase and continuous phase range from $1.5-9.0$ $\mathrm{mm} / \mathrm{s}$ and $4.8-21 \mathrm{~mm} / \mathrm{s}$. Slug formed spontaneously when the liquid meet each other at the T-junction.

Images of the slug break up were recorded using a high speed camera system (RedLake Inc) mounted onto the microscope, as shown in Figure 2. Images are taken at rates ranging from $250-5000 \mathrm{fps}$, depending on the frequency of slug formation. Image $J$, an image processing software, was used for analysis. Different flow ratios were controlled by using different syringe sizes. For example for a flow ratio of 0.27 , a syringe size of 2.5 $\mathrm{ml}$ was used as disperse phase while syringe size of $5 \mathrm{ml}$ was used for the continuous phase. Experiments were carried out with flow ratio of $0.35,0.27$ and 0.15 respectively, as shown in Table 1 . The flowrates were then adjusted accordingly while the process of image recording was repeated.

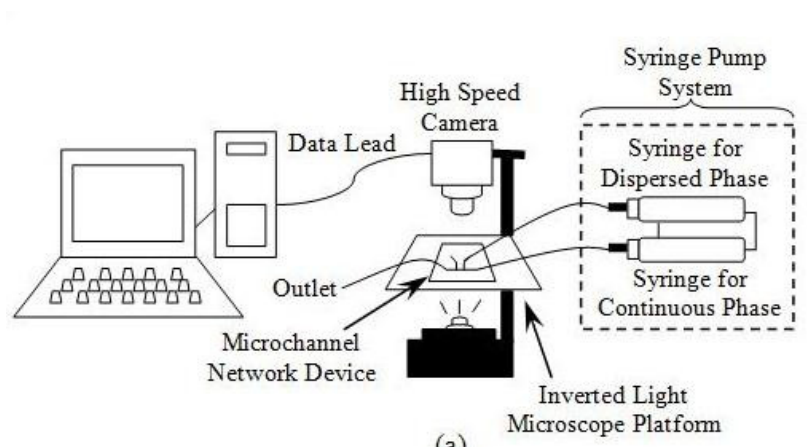

(a)

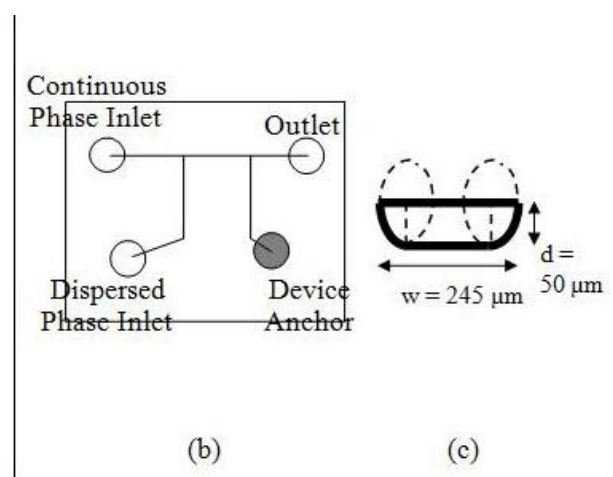

(c)

Fig. 2: Schematic representation of

(a) The setup for this experiment; (b) The glass microfluidic device with the continuous phase flowing along the main channel while the disperse phase from the side arm. Both phases meet at the T-junction flowing downstream towards the outlet.

(c) The dimension of the channel assumed to be a bowl shape, in which the cross sectional area is equivalent to a rectangular shape with a quarter circle at both ends.

\begin{tabular}{|c|c|c|}
\hline Disperse phase syringe, $m l$ & Continuous phase syringes, $m l$ & Flow ratio \\
\hline 2 & 5 & 0.35 \\
\hline 2 & 10 & 0.27 \\
\hline 1 & 5 & 0.14 \\
\hline
\end{tabular}

Table 1: Combinations of different BD standard plastic syringe size giving different flow ratios 


\section{RESULTS AND DISCUSSION}

Surface tensions of acetonitrile and tetradecane are $28.46 \mathrm{mN} / \mathrm{m}$ and $25.97 \mathrm{mN} / \mathrm{m}$ respectively while the interfacial tension of acetotnitrile/tetradecane system is 15.84 $\mathrm{mN} / \mathrm{m}$. The measurements were carried out in a digital tensiometer (K10 ST, Kruss Instrument). Dynamic viscosities of tetradecane and acetonitrile are 2.27 and $0.38 \mathrm{mPaS}$ respectively [12].

Advancing and receding contact angles of the tetradecane slug are measured from images taken during experiment. The ranges of angles are $125^{\circ}-150^{\circ}$ and $40^{\circ}-100^{\circ}$ respectively, depends on flowrate and flow ratio.

Slug lengths were measured from images taken throughout the experiment. The discussion below excludes flow ratio at 0.42 because of limitation of the high speed camera in which the images are not sufficiently sharp for measurement and calculation.

\subsection{At Relatively Low $W e_{e f f}\left(W e_{e f f}<2.0 \times 10^{-4}\right)$}

At relatively low $W e_{\text {eff }}$ and across different flow ratio, disperse phase was observed to have a clean snap off at the corner of the side and the main channel, as shown in Fig. 3.

Symmetry of the disperse phase into the main channel is disturbed when it almost occupies the cross sectional area of the main channel (Fig. 3a). The disperse phase then fully occupies the cross sectional area of the main channel and blocks it while elongating in the main channel (Fig. 3b). Throughout the process, rear interface in the junction is forced to change from convex in to a concave shape (Fig. 3c), indicating pressure build up in upstream of the continuous phase. The pressure built up increases continuously while the rear interface is being displaced downstream. As the interface approaches the corner of the T-junction and just before breaking up, a thin but visible disperse phase connecting neck was generated between the disperse phase in the main channel and the disperse phase in the side channel (Fig. 3d). However, the plane view thickness and the length of this connecting neck are relatively small and a clean snap off at the junction is reasonably assumed.

Due to the relatively short area available for shear and the explicit change in the shape of the rear disperse phase interface in the main channel, it is clearly shown that hydrodynamic plays an important role in slug break up at relatively low $W e_{e f f}$ flow.
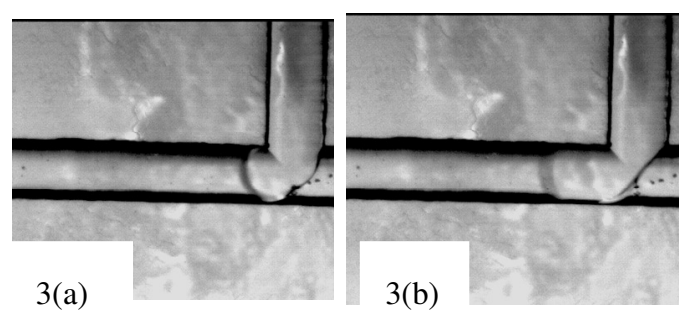

3(b)
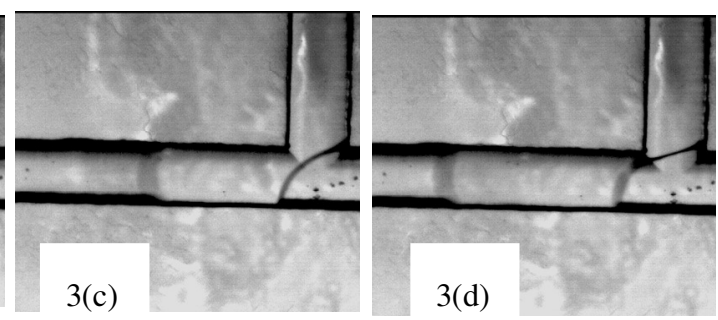

Fig. 3: Images of slug break up captured by high speed camera at $W e_{e f f}=8.8322 \times 10^{-5}$ and flow ratio of 0.35 . The interval between images is $80 \mathrm{~ms}$. Clean snap-off takes place during slug break-up. 


\subsection{At Intermediate $W e_{\text {eff }}\left(2.0 \times 10^{-4}<W e_{\text {eff }}<5.5 \times 10^{-4}\right)$}

As the total flow rate is further increased, the disperse phase slug growth in the main channel is approximating to that at relatively low $W e_{\text {eff }}$ (Fig. $4 \mathrm{a}, 4 \mathrm{~b}, 4 \mathrm{c}$ ) but the increase flow rate in the disperse phase causes a connecting neck of the disperse phase to evolve into a short trail of thin laminar flow before breaking up a short distance downstream of the T-junction (Fig. 4d). The thin laminar flow layer provides some surface area for shear to take place.

Analyses from images show that both hydrodynamic force and shear stress play important role in slug break up.
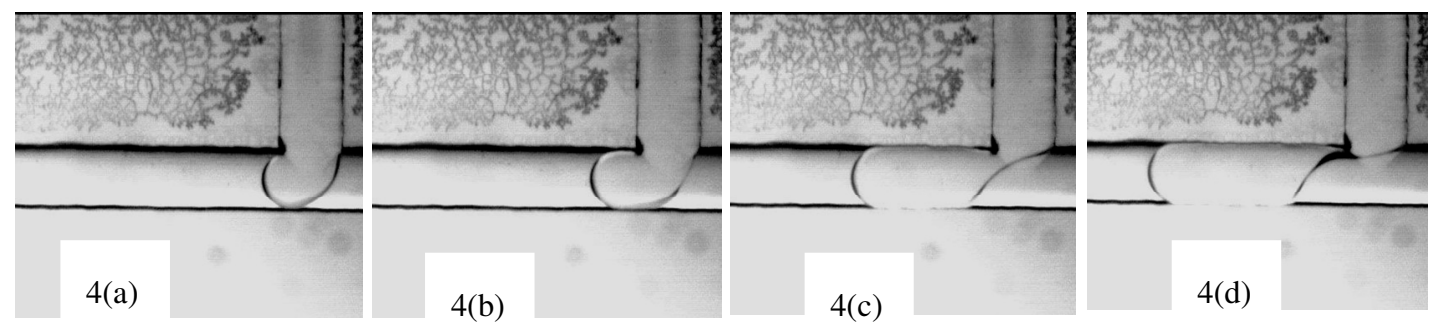

Fig. 4: Slug break up at intermediate $W e_{\text {eff }}, W e_{\text {eff }}=5.0 \times 10^{-4}$ and flow ratio $=0.35$. Images were taken at interval of $20 \mathrm{~ms}$. Small connecting neck exists before slug break-

up.

\subsection{At Relatively High $W e_{e f f}\left(W e_{e f f}>5.5 \times 10^{-4}\right)$}

As flow rates of both disperse phase and continuous phase are increased, the break up mechanism varies from previous cases. The continuous phase pushes the extruding disperse phase in the junction towards main channel downstream, before it can fully occupy the entire cross sectional area of the main channel. This causes increase in total contact area between both phases (Fig. 5a, 5b).

Compared to low and intermediate $W e_{\text {eff }}$, the change of the shape of the rear interface in the T-junction was not obvious and the plane view rear interface in the T-junction and downstream main channel did not approximate to the top width of the microchannel (Fig. $5 \mathrm{c})$, at any time throughout the break up process.

Shear interaction between the disperse phase and the continuous phase in the main channel causes elongation of the disperse phase laminar flow region in the main channel while the slug breaks off from the laminar flow region (Fig. 5d).
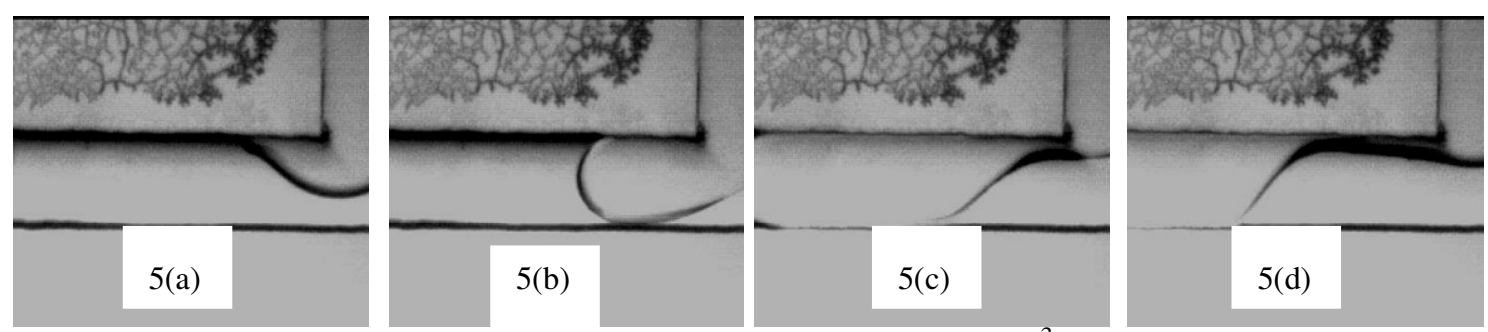

Fig. 5: Slug break up at relatively high $W e_{\text {eff }}, W e_{\text {eff }}=1.18 \times 10^{-3}$ and flow ratio $=0.35$. Images were taken at interval of $36 \mathrm{~ms}$. A large disperse phase laminar flow region formed downstream in the main channel. Slug breaks up at the tip of the region in the main channel. 
The experimental data and calculation is summarised in Table 2. It shows that hydrodynamic force is an important factor in slug break up at relatively low $W e_{\text {eff. }}$ At intermediate $W e_{e f f}$, both shear stress and hydrodynamic force are important for slug break up. At relatively high $W e_{\text {eff, }}$, the break up is dominated by shear force between both phases in the main channel.

\begin{tabular}{|l|l|l|l|l|}
\hline Flow ratio $=\mathbf{0 . 3 5}$ & $8.83 \times 10^{-5}$ & $2.28 \times 10^{-4}$ & $4.34 \times 10^{-4}$ & $9.89 \times 10^{-4}$ \\
\hline$W e_{\text {eff }}$ & $3.50 \times 10^{-11}$ & $1.67 \times 10^{-10}$ & $2.42 \times 10^{-10}$ & $4.51 \times 10^{-10}$ \\
\hline Shear force, $F_{\tau}$ & $1.89 \times 10^{-5}$ & $5.00 \times 10^{-5}$ & $7.46 \times 10^{-5}$ & $8.36 \times 10^{-5}$ \\
\hline Hydrodynamic force, $F_{h+c}$ & $1.86 \times 10^{-6}$ & $3.34 \times 10^{-6}$ & $3.24 \times 10^{-6}$ & $5.39 \times 10^{-6}$ \\
\hline Ratio of forces, $F_{\tau} / F_{h+c}$ & 1.86 \\
\hline Flow ratio $=\mathbf{0 . 2 7}$ & $1.69 \times 10^{-4}$ & $2.22 \times 10^{-4}$ & $5.91 \times 10^{-4}$ & $8.88 \times 10^{-4}$ \\
\hline$W e_{e f f}$ & $3.90 \times 10^{-11}$ & $1.04 \times 10^{-10}$ & $1.65 \times 10^{-10}$ & $2.40 \times 10^{-10}$ \\
\hline Shear force, $F_{\tau}$ & $1.68 \times 10^{-5}$ & $2.44 \times 10^{-5}$ & $3.09 \times 10^{-5}$ & $3.21 \times 10^{-5}$ \\
\hline Hydrodynamic force, $F_{h+c}$ & 10 & $5.34 \times 10^{-6}$ & $7.48 \times 10^{-6}$ \\
\hline Ratio of forces, $F_{\tau} / F_{h+c}$ & $2.32 \times 10^{-6}$ & $4.26 \times 10^{-6}$ & \\
\hline Flow ratio $=\mathbf{0 . 1 5}$ & $7.25 \times 10^{-5}$ & $1.13 \times 10^{-4}$ & $1.72 \times 10^{-4}$ & $2.88 \times 10^{-4}$ \\
\hline$W e_{e f f}$ & $7.32 \times 10^{-11}$ & $9.04 \times 10^{-10}$ & $1.15 \times 10^{-10}$ & $2.69 \times 10^{-10}$ \\
\hline Shear force, $F_{\tau}$ & $6.44 \times 10^{-5}$ & $6.21 \times 10^{-5}$ & $8.05 \times 10^{-5}$ & $7.55 \times 10^{-5}$ \\
\hline Hydrodynamic force, $F_{h+c}$ & $4.44 \times 10^{-5}$ & $1.43 \times 10^{-6}$ & $3.56 \times 10^{-6}$ \\
\hline Ratio of forces, $F_{\tau} / F_{h+c}$ & $1.65 \times 10^{-6}$ & $1.46 \times 10^{-6}$ &
\end{tabular}

Table 2: calculation of force ratio according to $W e_{\text {eff }}$ in different syringe combination giving different flow ratios

In each flow ratio, $W e_{\text {eff }}$ is increased by increasing in overall flowrates in both syringes. In Flow ratio $=0.35$, when $W e_{\text {eff }}<2.5 \times 10^{-4}$, tetradecane slugs have clean snap off taken place at the corner of T-junction. As the $W e_{\text {eff }}$ is increased, a disperse phase small trail starts to form at the corner. A disperse phase laminar flow region formed in the main channel as $W e_{\text {eff }}$ is further increased. Throughout the experiment, phenomena of clean snap off until failure of the slug formation at the T-junction is observed.

In flow ratio $=0.27$, the experiment starts with clean snap off of slug formation. However, a small trail is formed as increment in $W e_{\text {eff }}$ is carried out. Further increment in $W e_{\text {eff }}$ causes the tetradecane slugs to be produced from the laminar flow region formed in the main channel.

In third experiment, in which $1 \mathrm{ml}$ syringe is used in disperse phase while $5 \mathrm{ml}$ syringe is used in continuous phase to give flow ratio of 0.14 , tetradecane slug formation takes place across a wide range from $7.25 \times 10^{-5}$ until $1.72 \times 10^{-4}$. A trail is formed at the corner for slug formation as $W e_{\text {eff }}$ is increased to $2.88 \times 10^{-4}$. Further increase in $W e_{\text {eff }}$ results in the phenomenon failure at $W e_{\text {eff }}=7.23$ $\mathrm{x} 10^{-4}$, however meaningful results are limited due to capability of the high speed camera. 
The preliminary study shows a general trend that the phenomena of slug formation in a Tjunction, ie clean snap off, formation of a small trail at the corner and formation of a disperse phase laminar flow region depends on the $W e_{\text {eff }}$ but independent of flow ratio.

Validation is carried out by plotting disperse phase slug length against $W e_{\text {eff }}$, as shown in Fig. 6. It is found that slug length approaches infinity when $W e_{\text {eff }}$ is extremely low. As $W e_{\text {eff }}$ increases gradually, the slug length generated drops significantly until $W e_{\text {eff }} \sim 1 \times 10^{-}$ ${ }^{4}$. Further increase in $W e_{\text {eff }}$ has negligible effect on the slug length. The plots are similar to the trend in Hagen Poisuelle equation, with $t$ showing that the slug length as an inverse function of pressure drop in the main channel. Fig. 6 confirms the suitability of utilising $\boldsymbol{W} \boldsymbol{e}_{e f f}$ as characterising parameter especially at relatively low flow rate.

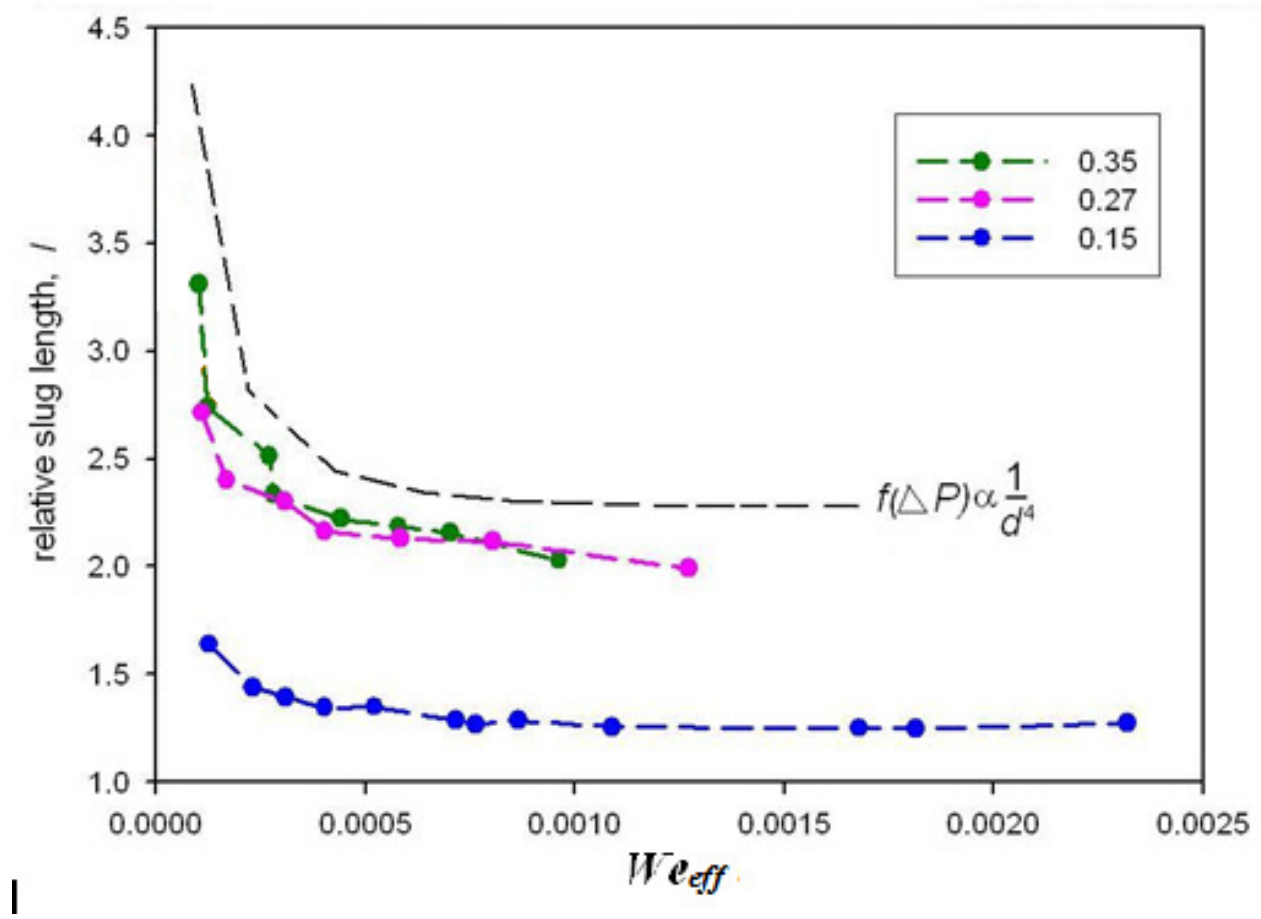

Fig. 6: Plotting of relative disperse phase slug length to $W e_{\text {eff. }}$

\section{CONCLUSION}

Understanding the fundamental physics of slug formation in a microchannel $\mathrm{T}$ junction is important in exploring further potential application of the phenomenon into other fields. However the flow dynamic is always complicated and difficult to model with simulation any software available.

Although the experiment was carried out only with a single immiscible liquid-liquid system, the qualitative result and simplified analysis method still give a few important points about slug break up phenomenon in a microchannel T-junction.

From the experimental work, it can be concluded that at relatively low $W e_{\text {eff }}$, $\left(W e_{\text {eff }}<\right.$ $2.0 \times 10^{-4}$ ), in which disperse phase slug clean snap off occurs, the ratio of shear force to the hydrodynamic force is always less than $3.0 \times 10^{-6}$. hydrodynamic force plays an 
important role in disperse phase slug break up at relatively low $W e_{\text {eff }}$ with a clean snap off at the T-junction. At intermediate $W e_{\text {eff, }}\left(W e_{\text {eff }}=2.5-5 \times 10^{-4}\right)$, the force ratio is approximately $3.0-5.0 \times 10^{-6}$. A small trail of disperse phase extruding into the main channel, resulting in both hydrodynamic force and shear force playing important role in slug break up. In the case when $W e_{\text {eff }}>5 \times 10^{-4}$, disperse phase slug breaks up from a laminar flow region in the main channel with the force ratio at approximately $4.5-6.0 \mathrm{x}$ $10^{-6}$. large contact surface area of the disperse phase laminar flow region in the main channel provides large surface area for shear interaction between both phases.

Further analysis justifies the utilization of $W e_{\text {eff }}$ as a characterizing parameter.

\section{FUTURE WORK}

Experimentations with different immiscible liquid-liquid systems are being carried out in verifying the model and establishing the theory for slug break up across different flow ratio and viscosity ratios. In addition, the use of a high speed camera which gives higher resolution and higher frames per second, fps, are useful in analysis.

\section{ACKNOWLEDGEMENT}

The author would like to acknowledge Ministry of Higher Education Malaysia (MOHE) Fundamental Research Grant Scheme (FRGS/2/2010/TK/UNIM/03/3) for funding the research project.

\section{REFERENCES}

[1] Burns, J. R., and Ramshaw C., The intensification of rapid reactions in multiphase systems using slug flow in capillaries, Lab-on-a-chip, 2001, 1, pp. 10-15

[2] Song H., Tice J. D., and Ismagilov R. F., A microfluidic system for controlling reaction networks in time, Angw. Chem., 2003, pp. 768-772

[3] Tice J. D., Lyon A. D., and Ismagilov R. F., Effects of Viscosity on Droplet Formation and Mixing in Microfluidic Channels, Analytica Chimica Acta 507, 2004, pp. 73-77

[4] Niu, X.Z., Zhang, B., Marszalek, R.T., Ces, O., Edel J.B., Klug, D.R. and deMello, A.J. Droplet-based compartmentalization of chemically separated components in two-dimensional separations, Chem. Commun., 2009, 7(41), pp. 6159-6161

[5] Mazutis, L. And Griffiths, A.D., Preparation of Monodisperse Emulsions by Hydrodynamic Size Fractionation, Applied Physics Letters, 2009, 95, pp. 204103- 04105

[6] Srinivasan, V., Pamula, V.K. and Fair, R.B., An Integrated Digital Microfluidic Lab-on-achip for Clinical Diagnostics on Human Physicological Fluids, Lab-on-a-chip, 2004, 4, pp. 310-315

[7] Hinze J., Fundamentals of the hydrodynamic mehcanism of splitting in dispersion processes, AIChE, 1955, 1, pp. 289-295

[8] Zhang D. F., and Stone H. A., Drop formation in viscous flows at a vertical capillary tube, Phys. Fluids, 1997, 9, pp. 2234-2242 
[9] Thorsen T., Roberts. R. W., Arnold F. H., and Quake S., Dynamic Pattern Formation in a Vesicle-Generating Microfluidic Device, Phy. Rev. Lett., 2001, pp. 4163-4166

[10] Garstecki P., Fuerstman M., Stone H. A., Whitesides G. M., Formation of droplets and bubbles in a microfluidic T-junction - Scaling and mechanism of break up, Lab-on-a-chip, 2006, 437

[11] Che-Hisn Lin, Gwo-Bin Lee, Yen-Heng Lin, and Guan-Liang Chang, A fast prototyping process for fabrication of microfluidic systems on soda-lime glass, J. Micromech. Microeng., 2001, 11, pp. 726-732

[12] Perry's Chemical Engineers' Handbook, 1997

\section{NOMENCLATURE}

$\begin{array}{ll}\mathrm{Re} & \text { Reynolds number } \\ \mathrm{We} & \text { Weber Number } \\ \mathrm{Ca} & \text { Capillary Number } \\ \text { Eff } & \text { Effective } \\ \rho & \text { density, } \mathrm{kg} / \mathrm{m}^{3} \\ \mathrm{~L} & \text { characteristic length, } \mathrm{m} \\ u & \text { flow velocity, } \mathrm{m} / \mathrm{s} \\ \mu & \text { viscosity, } \mathrm{kg} / \mathrm{m}^{2} \mathrm{~s} \\ r & \text { radius, } \mathrm{m} \\ h & \text { height of the channel, } \mathrm{m} \\ w & \text { width of the channel, } \mathrm{m} \\ \mathrm{D}_{\text {hyd }} & \text { Hydraulic Diameter, } \mathrm{m} \\ \mathrm{G} & \text { shear rate, } \\ \text { Cont } & \text { Continuous Phase } \\ \text { Disp } & \text { Dispersed Phase } \\ \gamma & \text { Interfacial tension } \\ Q & \text { Volumetric Flowrate, } \mathrm{kg} / \mathrm{m}^{3}\end{array}$

